\title{
A Lesion Mimicking Malignancy: Granulomatous Orchitis
}

\author{
(1) Çiğdem Öztürk¹, (1) Esra Paşaoğlu², (0) Tuğçe Bölme Şavlı³ \\ ${ }^{1}$ Recep Tayyip Erdoğan University Training and Research Hospital, Clinic of Pathology, Rize, Turkey \\ 2 University of Health Sciences Turkey, Bağcllar Training and Research Hospital, Clinic of Pathology, Istanbul, Turkey \\ ${ }^{3}$ Gaziantep Cengiz Gökçek Maternity and Children's Hospital, Clinic of Pathology, Gaziantep, Turkey
}

\begin{abstract}
Granulomatous orchitis is a rare disease with mixed chronic and granulomatous inflammation. Various factors cause granulomatous inflammation in the testicles, and it may accompany malignancies. Radiologically, granulomatous orchitis can be confused with malignancy. This paper presents the differential diagnoses of granulomatous orchitis. A 52-year-old man with testicular swelling was referred to the urology clinic. A palpable mass was detected by physical examination. Ultrasonography revealed a solid, heterogeneous $2.5 \mathrm{~cm}$ mass suspected as a malignancy in the right testes. The patient underwent elective orchiectomy. Microscopically, the testicle showed necrotising granulomatous inflammation accompanied by an inflammatory infiltrate that destroyed the testicular structure and caused rete testis hyperplasia. Radiologically, granulomatous orchitis can be confused with malignancy. Sufficient samples should be taken to exclude malignancy. Idiopathic granulomatous orchitis can be diagnosed after excluding all possible causes of granulomatous orchitis.
\end{abstract}

Keywords: Granulomatous orchitis, malignancy, testicle

\section{Introduction}

Granulomatous orchitis is a rare disease with mixed chronic and granulomatous inflammation. Tuberculosis, brucellosis, actinomycosis, and sarcoidosis are known aetiological factors. Idiopathic granulomatous orchitis (IGO), an inflammatory condition of the testis of unknown aetiology, is rarely encountered (1). Since the ultrasonographic image demonstrated diffuse hypoechoic or focal hypoechoic areas, it is confused with malignancy. Therefore, patients often undergo orchiectomy, and IGO is diagnosed only through histopathological examination (2).

\section{Case Presentation}

A 52-year-old man with testicular swelling was referred to the urology clinic. A palpable mass was detected by physical examination. Ultrasonography revealed a solid heterogeneous mass suspected as a malignancy in the right testes. On biochemical examination, beta human chorionic gonadotropin, alpha-fetoprotein and lactate dehydrogenase levels were within their normal range. The patient underwent elective orchiectomy. On macroscopic examination, the right testicle contained an exophytic mass which, upon dissection, demonstrated a necrotic nodule measuring $2.5 \times 1.5 \times 1.5 \mathrm{~cm}^{3}$ (Figure 1A). The whole lesion was examined. On microscopic examination, the testicle showed multiple necrotising granulomas and rete testis hyperplasia (Figure 1B). There was granulomatous inflammation accompanied by an inflammatory infiltrate consisting of plasma cells and lymphocytes that destroyed the testicular structure (Figure 2A, B), which was accompanied with rete testis hyperplasia (Figure 3). Microorganisms were not seen in periodic acid-Schiff (PAS) and Ziehl-Neelsen (EZN) staining. Burned-out/regressed germ cell tumours were excluded with immunohistochemical study. The histopathological diagnosis was chronic necrotising granulomatous orchitis. The patient underwent clinical, serological and radiological tests after pathological diagnosis, but no potential factor was detected.

\section{Discussion}

IGO most commonly occurs at age 50-70 years, although cases have been reported in all ages (2). IGO can be acute or chronic. In the acute form, patients present with sudden onset of pain, while in the chronic form, they present with unilateral scrotal swelling. Patients can also present with fever, haematuria, dysuria and hydrocele (3).

The aetiology of IGO is not known exactly, but it is thought to be related to trauma. Additionally, autoimmune diseases and infections have been associated with IGO (2). IGO can clinically mimic malignancy. Testicular trauma, surgery, history

Cite this article as: Öztürk Ç, Paşaoğlu E, Bölme Şavlı T. A Lesion Mimicking Malignancy: Granulomatous Orchitis. Bull Urooncol 2021;20(2):126-128

Address for Correspondence: Çiğdem Öztürk, Recep Tayyip Erdoğan University Training and Research Hospital, Clinic of Pathology, Rize, Turkey Phone: +90 5068069555 E-mail: cigdemtopuksak@gmail.com ORCID-ID: orcid.org/0000-0003-2587-214X 


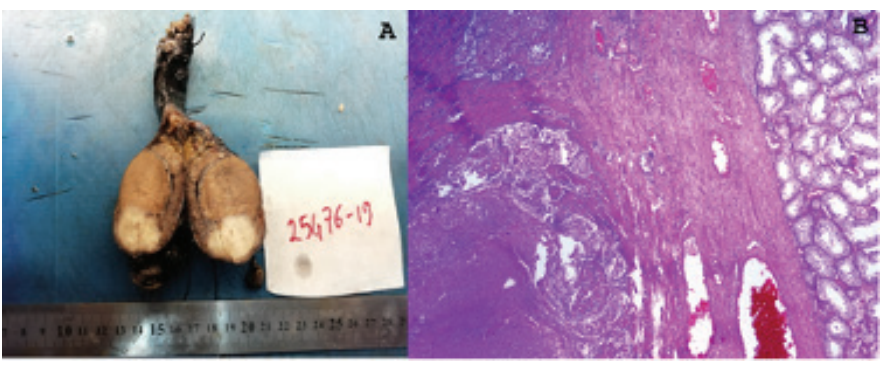

Figure 1. A: Macroscopic view of the testicle which demonstrated a necrotic nodule. B: Microscopic view of the normal testicular tissue on the right and lesion area on the left (haemotoxylin and eosin staining, $\times 40$ )

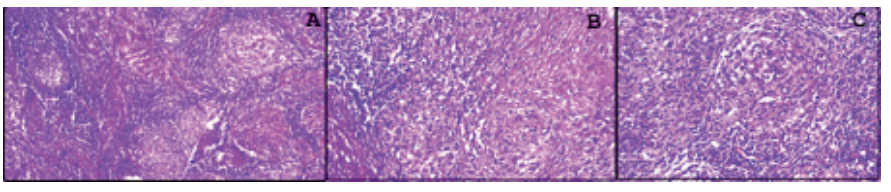

Figure 2. A: Multiple necrotising granulomas (hematoxylin and eosin staining $(\mathrm{HE}), \times 100)$. B: Multiple granuloma structures $(\mathrm{HE}, \times 200)$. C: Granuloma structure accompanied by an inflammatory infiltrate $(\mathrm{HE}, \times 200)$

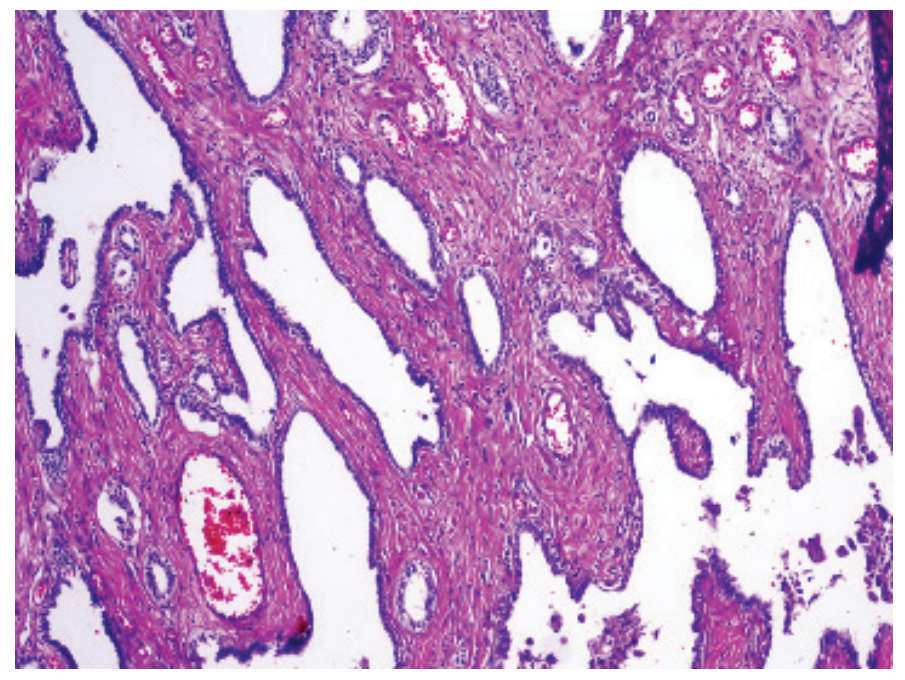

Figure 3. Rete testis haemotoxylin $(\mathrm{HE}, \times 100)$

of tuberculosis and urinary tract and epididymis infections may raise clinical suspicion for IGO (4).

Distinguishing IGO from malignancy is extremely challenging because of the destruction of the testicular tissue, as shown in ultrasonography. Therefore, orchiectomy is often performed (2). On histopathological examination, the granulomatous inflammatory infiltrate consisting of plasma cells and lymphocytes invade the seminiferous tubules and germ cells degenerate. Fibrosis develops in the later period (5).

Inflammatory and infectious factors should be considered in the differential diagnosis. The most common cause of granulomatous inflammation is tuberculosis. The presence of granulomas with caseification necrosis accompanied by Langhans-type giant cells and the presence of microorganisms in the acid-fast histochemical staining suggest tuberculosis (6). Other factors in the differential diagnosis are syphilis, leprosy, brucella and fungal infections. In these factors, the specific morphological appearance of granulomas; presence of microorganisms in histochemical stains such as Warthin-Starry, EZN and PAS; and clinical laboratory findings are helpful in the diagnosis (7). Sarcoidosis that rarely involves the genitourinary system should be also considered. Non-caseating granulomas, minimal lymphocytic infiltration, Schauman basophilic, asteroid bodies and systemic involvement in patients support the diagnosis of sarcoidosis (8). Granulomatous seminoma on histopathological examination should also be considered in the differential diagnosis. The presence of intratubular germ cell neoplasia, immunohistochemical presence of a tumour such as OCT3/4 and CD117 and placental alkaline phosphatase are also helpful in the differential diagnosis (9). Malignant lymphoma is another neoplasia that should be included in the differential diagnosis. In IGO, lymphoma is excluded if the inflammatory infiltrate is not monotonous and shows polyclonal pattern on immunohistochemical staining and partially preserved tubular structure of the testis (10).

In the present case, malignancy was considered following clinical and ultrasonographic examinations. Histopathologically, the granuloma structure specific to infectious agents was not observed, and organisms were not detected histochemically. On morphological examination, burned-out/regressed germ cell tumour was not considered and was supported by immunohistochemical studies. Thus, the present case was evaluated as IGO after all other causes were excluded. Moreover, rete testis hyperplasia was present. Rete testis hyperplasia is a non-neoplastic lesion that mimics a malignancy of unknown aetiology (11). The accompanying rete testis hyperplasia in our case may be due to degeneration resulting from granulomatous inflammation.

Radiologically, granulomatous orchitis can be confused with malignancy. Thus, sufficient samples should be taken to exclude malignancy. IGO can be diagnosed after excluding all possible causes of granulomatous orchitis.

\section{Acknowledgements}

Publication: The results of the study were not published in full or in part in form of abstracts.

Contribution: There is not any contributors who may not be listed as authors.

Conflict of Interest: No conflict of interest was declared by the authors.

Financial Disclosure: The authors declared that this study received no financial support.

\section{Ethics}

Informed Consent: The patient provided written informed consent which includes the case details and agreed to the publication of histopathological images.

Peer-review: Externally peer-reviewed.

\section{Authorship Contributions}

Concept: Ç.Ö., Design: Ç.Ö., E.P., Data Collection or Processing: Ç.Ö., T.B.Ş., Analysis or Interpretation: T.B.Ş., Literature Search: Ç.Ö., E.P., Writing: Ç.Ö., E.P., T.B.Ş. 


\section{References}

1. Civelli VF, Heidari A, Valdez MC, et al. Case of testicular granulomatous inflammation mistaken for malignancy: tuberculosis identified post orchiectomy. I Investig Med High Impact Case Rep 2020;8:2324709620938947. doi: 10.1177/2324709620938947.

2. Roy S, Hooda S, Parwani AV. Idiopathic granulomatous orchitis. Pathol Res Pract 2011;207:275-278.

3. Raju GC, Naraynsingh V. Idiopathic granulomatous orchitis. Trop Geogr Med 1985;37:188-189.

4. Sadeghi A, Chaikin D, Calhoun S. Testicular tuberculosis: An uncommon complication after treatment of urothelial carcinoma. Radiol Case Rep 2020;15:2285-2293.

5. Wegner HE, Loy V, Dieckmann KP. Granulomatous orchitis--an analysis of clinical presentation, pathological anatomic features, and possible etiologic factors. Eur Urol 1994;26:56-60.

6. Salmeron I, Ramirez-Escobar MA, Puertas F, et al. Granulomatous epididymo-orchitis: sonographic features and clinical outcome in brucellosis, tuberculosis and idiopathic granulomatous epididymoorchitis. J Urol 1998;159:1954-1957.

7. Varma R, Baithun S, Alexander S, Goh BT. Acute syphilitic interstitial orchitis mimicking testicular malignancy in an HIV-1 infected man diagnosed by Treponema pallidum polymerase chain reaction. Int J STD AIDS 2009;20:65-66.

8. anda T, Nagai S, Hamada K, et al. Sarcoidosis with bilateral epididymal and testicular lesions. Intern Med 2003;42:92-97.

9. Ulbright TM. The most common, clinically significant misdiagnoses in testicular tumor pathology, and how to avoid them. Adv Anat Pathol 2008;15:18-27.

10. Nistal M, Paniagua R. Non-neoplastic diseases of the testis. In: Bostwick DG, Cheng L, editors. Urologic surgical pathology. 2nd ed. China: Mosby; 2008:712.

11. Ozgur T, Akin MM, Gokce H, Davarci M. Adenomatous hyperplasia of the rete testis: not a true hyperplasia, just proliferation!. Contemp Oncol (Pozn) 2013;17:466-467. 